\title{
A Decision Making and Clustering Method Integration based on the Theory of Planned Behavior for Student Entrepreneurial Potential Mapping in Indonesia
}

\author{
Nova Rijati ${ }^{1,2 *}$ \\ Diana Purwitasari ${ }^{1}$ \\ Surya Sumpeno ${ }^{1}$ \\ Mauridhi Hery Purnomo ${ }^{1}$ \\ ${ }^{I}$ Department of Electrical Engineering, Faculty of Intelligent Electrical and Informatics \\ Technology, Institut Teknologi Sepuluh Nopember, Surabaya, Indonesia \\ ${ }^{2}$ Department of Informatics, Faculty of Computer Science, Universitas Dian Nuswantoro, Semarang, Indonesia \\ * Corresponding author's Email: nova.rijati@dsn.dinus.ac.id
}

\begin{abstract}
One of the Indonesia Government strategies in the human resources field is preparing peoples such that they can create new jobs. In the higher education level, all universities in Indonesia are encouraged to be able to produce young entrepreneurs from among students. However, not all of the students have the same entrepreneurial potential. The university management needs to map the students to be prepared as the prospective entrepreneurs. This study is proposed to reveal the hidden knowledge of student entrepreneurial potential mapping from the higher education database. The integration of the decision making model and clustering method based on the theory of planned behavior is utilized to achieve this objective. The fuzzy multi-attribute method is applied in the decision making approach. Whereas, the k-means clustering is selected to generate the group of student entrepreneurial potency as the entrepreneurial potential mapping. Experimental results show that there are four identified clusters to present the student entrepreneurial potential levels. The first cluster consists of the students who have medium and high potential levels of $68 \%$ and $32 \%$, respectively. The second cluster consists of the students who have medium, high and very high potential levels of $19 \%, 69 \%$, and $12 \%$, respectively. The third cluster consists of the students who have high and very high potential levels of $50 \%$ and $50 \%$, respectively. While the fourth cluster consists of the students who have medium and high potential levels of $18 \%$ and $82 \%$, respectively.
\end{abstract}

Keywords: Student entrepreneurial intention, Student entrepreneurial potential, Entrepreneurial behavior, Theory of planned behavior, Fuzzy multi-attribute decision making.

\section{Introduction}

Entrepreneurship is a process of applying creativity and innovation in solving issues and seeking opportunities to make a better living [1]. Entrepreneurship does not an instant process and it relates a behavior that requires being planned. Based on the theory of planned behavior (TPB) [2], entrepreneurial activity is preceded by entrepreneurship intention that is influenced by three beliefs: attitude, subjective norm, and perceived behavioral control. These beliefs could lead someone into a successful entrepreneur. In the student entrepreneurship context, the contribution of attitudes belief on entrepreneurial activities could be autonomy and authority, economic opportunity and challenge, security and workload, self-realization and participation, and need for achievement [3-4]. The subjective norm belief could be interpreted as academic support because universities must provide entrepreneurship skills toward its scholars and encourage them to take entrepreneurs as their career [5]. The perceived behavioral control is usually an external factor such as resources and opportunities that align the intention and behavior $[6,7]$.

In Indonesia, student entrepreneurial potential development is one of the national strategic programs to increase the national economy standard [8]. This strategy is also designed to anticipate the era of demographic bonuses, where the population of productive age is larger than the non-productive age. This condition is predicted to reach a peak in 2028 to 2031 based on the Central Bureau of Statistics reports. In 1998, the Indonesian 
Government introduced the student entrepreneurship creativity program (SECP) to accelerate the growth of student entrepreneurs. Further, entrepreneurship was publically declared as a compulsory subject to all universities in Indonesia since 2012.

Each university in Indonesia should provide adequate facilities and environments to encourage the abilities and skill of student entrepreneurship. A student entrepreneurial potential mapping should be designed for decision making to implement the continuous entrepreneurship program based on the potential of respective students. Unfortunately, there is no definitive model that can be adapted to present the student entrepreneurial potential mapping for those purposes above. Referring to the current state, the Indonesian higher education database just mainly focuses on transactional data of education, research, and community service. There is no related data of the national student entrepreneurship that can be used for decision making in the entrepreneurship program directly. However, the Indonesian higher education database contains many attributes of students and feasible to be considered to construct the TPB model of the student entrepreneurial potential mapping.

Recognizing the student entrepreneurial potential through the TPB does not ease practically. Most researchers utilized questionnaire-based data to elaborate and map the student entrepreneurial potential. However, there are many disadvantages in the use of the questionnaire to collect the behavioral characteristics of students. Students perhaps in a hurry to fill out or answer questionnaires, unable to answer difficult questions, give answers that are not forthright and give answers that are not under the actual situation even though they fill out a blind or closed questionnaire with anonymous. All of these cases will produce a questionnaire with low validity so that difficult to gain a valid conclusion. Besides, questionnaire-based student entrepreneurial data analyses are usually applied in the limited or regional area and difficult to generalize into the national scale policies.

The TPB approach has been widely used for the entrepreneurship model analysis. However, there are only a few studies deal with the entrepreneurial clustering method based on the multi-attribute decision making model. The $k$-means clustering on a dataset consisting of a simple multi-attribute rating technique (SMART) ranked, which are varied value and weight attribute to generates simplified attribute [8]. The integration of the fuzzy analytic hierarchy process (AHP) technique with k-means clustering to segment customers into dominant characteristics-based clusters [9]. The multiple- criteria decision making (MCDM) technique cluster evaluation on the analysis dataset, which increases the effectiveness of evaluation processing and generates better clusters $[6,10]$. The information preference-based multi-criteria technique to generate a better cluster by combining the previous cluster with the clustering assembly technique [11]. The generating optimum cluster with dynamic multiobjective decision technique [12]. The MCDM optimization, which integrates simple additive weighting (SAW), a technique for order preference by similarity to ideal solution (TOPSIS), and Borda technique [13]. This technique is the most profitable decision on selecting tools to minimize production resources. Meanwhile, a combination of SAW, TOPSIS, and grey relational analysis (GRA) techniques could produce the best decision by minimizing the influence on assessing weight preference [14]. The other researcher measured entrepreneurship interest based on the TPB using fuzzy logic with five levels of entrepreneurship interest [15].

This study is proposed to develop a student entrepreneurship potential mapping for the decision making model by integrating the fuzzy multiattribute decision making (FMADM) and clustering techniques. It is expected to support decision making by determining the entrepreneurial potential level and map-based clustering method. The mapping for the student's entrepreneurial potential would then be displayed by applying the TPB's variables on the higher education database referring to the national standard's higher education. There is a strategic process to apply the knowledge discovery on the higher education database to generate the student entrepreneurial potential map. Meanwhile, the result of this research may help the university management to evaluate and compile an appropriate policy on generating the student entrepreneurial intention in the sense that the student entrepreneurial potential. However, the higher education database is sometimes not ready to use for decision making. An incomplete, vague, or inconsistent variable causes a fuzziness in the dataset $[7,18,19]$. To address this issue, the FMADM method is applied in this study.

Based on data type, FMADM could be divided into 3 types, which are fuzzy data, crisp data, and the combination of fuzzy and crisp data [33]. There are many methods in FMADM, such as SAW, weighted product (WP), elimination et Choix traduisant la realite (ELECTRE), TOPSIS, and AHP $[7,8,18]$. Some FMADM techniques also mixture one or more methods, such as SAW with TOPSIS [13], SAW with WP [22], and TOPSIS with a fuzzy cognitive map (FCM) [34]. The mixture of SAW 
and TOPSIS shows the most efficient method to determine the most appropriate decision alternative in the case of multi-attribute decision making [13, 14, 20-22]. Hence, this study will use the integration of the SAW and TOPSIS to address the fuzziness of the student entrepreneurial potential rank.

Technically, the FMADM is used to pick out the TPB variables that influence the student entrepreneurial intention. The intention may consist of a varied value and weight of attributes, which are formulated as alternatives solutions for assessing student entrepreneurship. In this case, the fuzzy logic is used to define a qualitative, inaccurate and vague variable such as an attitude variable. Overall, the use of the FMADM technique is to determine the decision on several incomplete, vague, or inconsistent variables-based alternatives [7]. This study also uses a clustering technique to generate student entrepreneurial clusters as student entrepreneurial potential mapping. The students in one cluster could have a very high characteristic similarity in the same cluster, but dissimilar the other students in a different cluster.

This paper is organized into several sections, as follows. Section 2 presents the fundamental of the theory of planned behavior. Section 3 presents the methodology of this study, including the dataset and the proposed method. The main proposed steps are defining the student entrepreneurial potential attributes, defining the student entrepreneurial potential rank, and creating the student entrepreneurial potential map. The experimental results and discussion of this study are presented in Section 4. Finally, the conclusions and future works of this study are summarized in Section 5.

\section{Theory of planned behavior (TPB)}

The TPB was originally introduced from the theory of reasoned action, which is proposed to predict the intention of individuals to involve in a behavior. The essence of TPB explained that each individual has a behavioral intention as the main self-control abilities in behaviors. This means that behavior achievement will be determined by both intention and behavioral control. The behavioral intention represents the strength of the individual willingness to perform a certain behavior. In TPB, the actual behavior can be influenced by behavioral intention, which is constructed by the three kinds of beliefs that are attitude, subjective norm, and perceived behavioral control [17, 38]. Fig. 1 shows the construction of TPB that is built from these three interrelated beliefs.

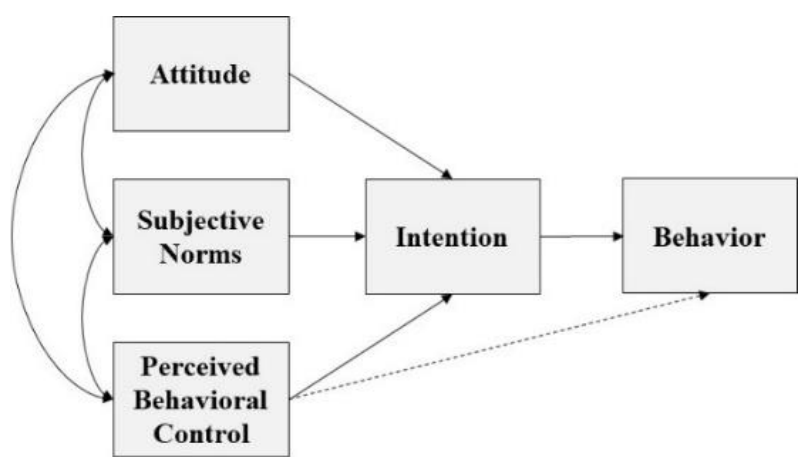

Figure. 1 Theory of planned behavior construction [17]

Attitude, the first major belief to determine the behavior intention, refers to the degree to which individuals in response to the favorable or unfavorable risks in the behavior.

The attitudes belief can be either a positive or negative assessment of something given in the environment. The attitude belief links to a certain outcome in behavior, or some attributes associated with this belief. To estimate this attitude outcome, one or more evaluation attributes can be used as the expectancy-value model [17], as formulated in Eq. (1).

$$
A_{B} \propto \sum_{i=1}^{k} b_{i} e_{i}
$$

where $A_{B}$ is an attitude toward behavior $B ; b_{i}$ is a behavior belief that performing the behavior $B$ with outcome $i$; and $e_{i}$ is an evaluation of outcome $i$.

The subjective norms refer to the external factors that influence individuals to do or not do a behavior. This normative belief can be in the form of pressure that comes from peers, society, institutions, or the other external environments. The relation between the subjective norm and normative beliefs is formulated in Eq. (2).

$$
S N \propto \sum_{i=1}^{k} n_{i} m_{i}
$$

where $S N$ is the subjective norm, $n_{i}$ is the normative belief with referent $i$, and $m_{i}$ is the motivation with referent $i$.

The third belief is the perceived behavioral control, which is an individual perception that affects the ease and difficulty to perform the behavior. This belief can be either resources or support that increase the strength of intention, but on the contrary, it can be either an obstacle or weakness that can decrease the individual intention to perform the behavior. The relation between the control 
beliefs and the perceived behavioral control is formulated in Eq. (3).

$$
P B C \propto \sum_{i=1}^{k} c_{i} p_{i}
$$

where $P B C$ is the perceived behavioral control, $c_{i}$ is the control belief with factor $i$, and $p_{i}$ is the power of factor $i$ to facilitate the behavior. These three beliefs above have a different level of contribution and impact on behavior intention respectively. The individual situation and condition will play a significant role in determining the degree of behavioral intention.

The TPB has been widely applied in various research fields, such as health service utilization, smoking, breastfeeding, drinking, complaining, leisure behavior, physical activity, psychological and psychosocial fields, and other behavioral researches [14]. The TPB based entrepreneurship research has immensely developed in the last 20 years and has contributed to entrepreneurship behavioral understanding [23]. In the university scope, some entrepreneurship researches concluded that attitude, subjective norms, and perceived behavioral control contribute significantly toward entrepreneurship interest and have the capability to encourage entrepreneurship behavior [3, 24, 25]. The other influencing factors are entrepreneurship education [26-31]. However, attitude is the strongest influencing variable [3] that possess cognitive and affective dimension to generate different impact toward entrepreneurship interest [32].

In student entrepreneurial related research, the TPB has also been used as well to explain and predict the planned behavior, such as to study entrepreneurial intentions [41], to explain and measure the student entrepreneurial intention of the first and the fourth year of business student [43], to study entrepreneurial intention through the moderation effect of start-up experience [42], to study the intention-action gap as the extent of TPB through the moderating role of entrepreneurial motivation between intention and behavior [40], and to study the relationship between intention and behavior based on the TPB to determine the level of student entrepreneurial motivation [39].

\section{Methodology}

\subsection{Dataset}

This study uses the Indonesian higher education dataset that is provided by the Indonesian Ministry of Research, Technology and Higher Education.

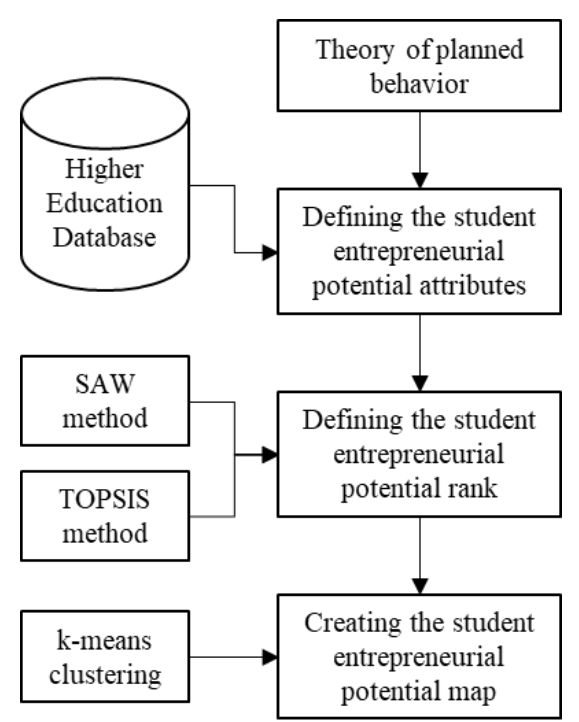

Figure. 2 The proposed method for the student entrepreneurial potential map

This dataset is public and it is the education standard in Indonesia according to the passing law no. $12 / 2012$ on higher education. The Indonesian higher education database is a centralized database that contains all of the recent statistics and information about higher education, such as students, lecturers, study programs, and universities in Indonesia.

\subsection{Methods}

The goal of this study is to design the student entrepreneurial potential mapping through the integration of decision making and clustering methods. The first stage of this study is defining the student attributes based on the TPB from the higher education database. The second stage is performing the student entrepreneurial potential rank using the FMADM method. Whilst, the third stage is grouping the student into the entrepreneurial potential clusters as the student entrepreneurial potential mapping. Overall, the proposed method to generate the student entrepreneurial potential map in this study is summarized in Fig. 2. The detail of the proposed method is explained step by step in the following sub-sections as follows.

\subsubsection{Defining the student entrepreneurial potential attributes}

The purpose of this stage is selecting the student attributes from the higher education database that represents the student entrepreneurial potential based on the TPB. There are three beliefs in the TPB construction that influence the student entrepreneurial intention. These beliefs are attitude, subjective norms, and perceived behavioral control [35]. Based on the higher education database, there 
are 14 student attributes, which can be categorized into the main three beliefs in the TPB [8].

The attitude belief can be represented through three attributes, which are the scholarship status, activist status, and type of entry. These attributes usually affect the attitude of students in behavior. Scholarships students generally have a higher attitude as the positive responsibilities form to their sponsors. Students who have an activity in the student organization generally have higher attitude concerns as their integrity as an activist. Whereas students who have higher competency when entering the university generally have a significant correlation to their attitudes.

The subjective norms belief can be represented through nine attributes, which are the parent occupation, parent income, grade point average (GPA), Indonesian language course score, English course score, research method course score, professional ethics course score, counseling course score, entrepreneurship course score. As a part the external factors to the entrepreneurial behavior, these attributes can be identified from the family and campus environments. The first two attributes, which are the parent occupation and income will influence the student decisions to perform the behavior. While the last nine attributes will affect the student's self-confidence in entrepreneurial behavior.

The perceived behavioral control can be represented through the business incubator status and college student entrepreneurship program (CSEP) status. These attributes are national competition programs from the government, which are designed to improve the student entrepreneurial abilities. Students who pass in these selection programs can be perceived as having fundamental abilities as prospective entrepreneurs. Thus, these selected attributes can represent the perceived behavioral control belief in the TPB model construction. All of these attributes that are defined from the higher education database and its relationships to the TPB beliefs are summarized in Table $1[8,16]$.

All of the defined attributes above are then used to construct the TPB model for student entrepreneurial potential, which is illustrated in Fig. 3. The student entrepreneurial potential in this study is constructed through the student entrepreneurial intention.

\subsubsection{Defining the student entrepreneurial potential rank}

Table 1. TPB beliefs components and defined attributes from the higher education database

\begin{tabular}{|c|l|l|}
\hline No. & TPB Beliefs & \multicolumn{1}{c|}{ Attributes } \\
\hline 1. & Attitudes & $\begin{array}{l}\text { Scholarship status, activists } \\
\text { status, type of entry }\end{array}$ \\
\hline 2. & $\begin{array}{l}\text { Subjective } \\
\text { norms }\end{array}$ & $\begin{array}{l}\text { Parents occupation, parents } \\
\text { income, GPA, Indonesian } \\
\text { language course score, English } \\
\text { course score, research method } \\
\text { course score, professional ethics } \\
\text { course score, counseling course } \\
\text { score, entrepreneurship course } \\
\text { score }\end{array}$ \\
\hline 3. & $\begin{array}{l}\text { Perceived } \\
\text { behavioral } \\
\text { control }\end{array}$ & $\begin{array}{l}\text { Business incubator status, CSEP } \\
\text { status }\end{array}$ \\
\hline
\end{tabular}

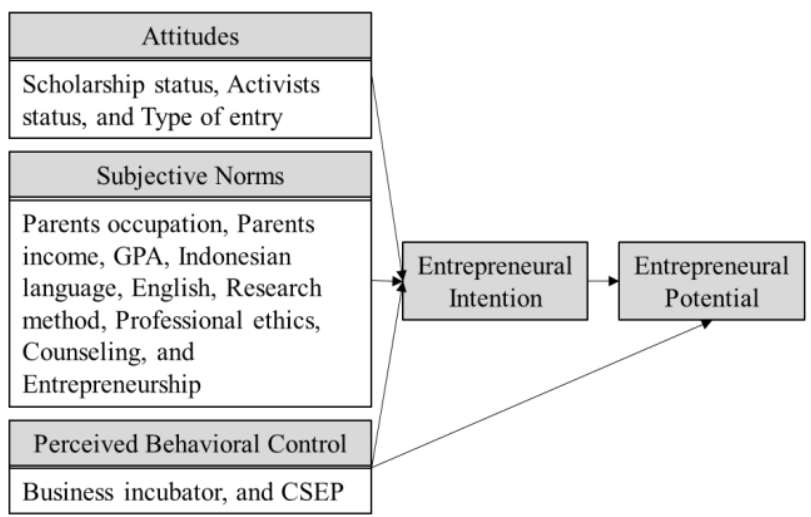

Figure. 3 The proposed TPB model construction for student entrepreneurial potential

The university management must do the decision making to create a policy in the student entrepreneurial programs. However, there are many limitations of resources to make a policy for all students. Hence, the managements require to select the potential student to run the student entrepreneurial programs policy effectively.

Unfortunately, the Indonesia higher education database contains many attributes that could not be generalized directly to select the student entrepreneurial potential. There is no decision support system model recently that can be used for decision making in the student entrepreneurial potential.

Based on the proposed TPB model in Fig. 1, the student entrepreneurial potential needs a decision making support system to accommodate all of the student entrepreneurial attributes and beliefs. The multiple criteria decision making (MCDM) perhaps the relevant method to overcome this situation [6]. Unfortunately, some of the attributes also contain either uncertainty or incomplete data. These two steps are needed to solve those issues, which are forming rank on each alternative based on 
Table 2. Student entrepreneurial potential criteria

\begin{tabular}{|c|l|c|}
\hline No & \multicolumn{1}{|c|}{ Criteria } & Code \\
\hline 1. & Scholarship status & A1 \\
\hline 2. & Activist status & A2 \\
\hline 3. & Type of entry & A3 \\
\hline 4. & Parents occupation & A4 \\
\hline 5. & Parents income & A5 \\
\hline 6. & GPA & A6 \\
\hline 7. & Indonesian language course score & A7 \\
\hline 8. & English course score & A8 \\
\hline 9. & Research method course score & A9 \\
\hline 10. & Professional ethics course score & A10 \\
\hline 11. & Counseling course score & A11 \\
\hline 12. & Entrepreneurship course score & A12 \\
\hline 13. & Business incubator status & A13 \\
\hline 14. & CSEP status & A14 \\
\hline
\end{tabular}

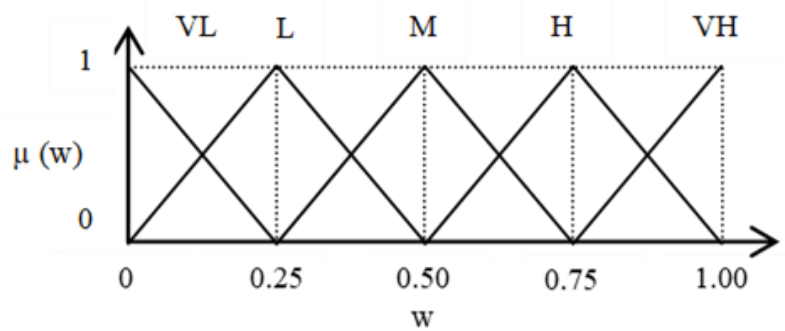

Figure. 4 Membership function for each Student entrepreneurial potential criteria

compatibility degree aggregate on all criteria, and ranking all alternative to obtaining the best alternative through de-fuzzy or fuzzy preference.

The level of student entrepreneurial potential criteria in this study are defined in Table 2, which are generated from the student entrepreneurial attributes in Table 1.

Each criterion will have a pre-determined variable and converted into a fuzzy number, as shown in Fig. 4. All of criteria are converted into the crisp numbers in the range of 0 to 1 with linguistic variable and fuzzy numbers as follows: very low $(\mathrm{VL})=0$; low $(\mathrm{L})=0.25$; medium $(\mathrm{M})=0.5$; high $(\mathrm{H})=0.75$, and very high $(\mathrm{VH})=1$.

The membership function for each linguistic variable is represented by a triangular fuzzy number. The VL variable has fuzzy number of $\{0.00 ; 0.00$; $0.25\}$, the $\mathrm{L}$ variable has fuzzy number of $\{0.00$; $0.25 ; 0.50\}$, the $\mathrm{M}$ variable has fuzzy number of $\{0.25 ; 0.50 ; 0.75\}$, the $\mathrm{H}$ variable has fuzzy number of $\{0.50 ; 0.75 ; 1.00\}$, and the VH variable has fuzzy number of $\{0.75 ; 1.00 ; 1.00\}$. The complete criteria, linguistic variables, and fuzzy numbers are listed in Table 3. After the linguistic variables and fuzzy numbers of criteria are defined, the composite SAW and TOPSIS method are then applied to determine the student entrepreneurial potential rank.
Table 3. Criteria code, linguistic variable, and fuzzy number

\begin{tabular}{|c|l|c|}
\hline $\begin{array}{c}\text { Criteria } \\
\text { Code }\end{array}$ & $\begin{array}{c}\text { Linguistic } \\
\text { Variable }\end{array}$ & $\begin{array}{c}\text { Fuzzy } \\
\text { Number }\end{array}$ \\
\hline A1 & Very High & $(0.75 ; 1.00 ; 1.00)$ \\
\hline A2 & Very High & $(0.75 ; 1.00 ; 1.00)$ \\
\hline A3 & High & $(0.50 ; 0.75 ; 1.00)$ \\
\hline A4 & High & $(0.50 ; 0.75 ; 1.00)$ \\
\hline A5 & Low & $(0.00 ; 0.25 ; 0.50)$ \\
\hline A6 & Medium & $(0.25 ; 0.50 ; 0.75)$ \\
\hline A7 & Low & $(0.00 ; 0.25 ; 0.50)$ \\
\hline A8 & Low & $(0.00 ; 0.25 ; 0.50)$ \\
\hline A9 & Medium & $(0.25 ; 0.50 ; 0.75)$ \\
\hline A10 & Low & $(0.00 ; 0.25 ; 0.50)$ \\
\hline A11 & Low & $(0.00 ; 0.25 ; 0.50)$ \\
\hline A12 & Medium & $(0.25 ; 0.50 ; 0.75)$ \\
\hline A13 & High & $(0.50 ; 0.75 ; 1.00)$ \\
\hline A14 & High & $(0.50 ; 0.75 ; 1.00)$ \\
\hline
\end{tabular}

\subsubsection{Simple additive weighting (SAW)}

The SAW method is a scoring method using a weighted linear combination based on the weighted average using some criteria. The evaluation score of each alternative is computed by the weighted sum of performance ratings. The SAW method is summarized in Algorithm 1, as follows.

\section{Algorithm 1: SAW algorithm \\ Input: Value set $\left\{x_{1}, x_{2}, \ldots, x_{i}\right\}$ of alternative $A_{i}$. \\ Output: Alternative preference values $V_{i}$. \\ Step 1. Define alternatives $\left\{A_{1}, A_{2}, \ldots, A_{i}\right\}$. \\ Step 2. Define criteria for references in decision} making $\left\{C_{1}, C_{2}, \ldots, C_{j}\right\}$.

Step 3. Define the rating of each alternative on each criterion.

Step 4. Define the weight or level of importance for each criterion $\left\{w_{1}, w_{2}, \ldots, w_{j}\right\}$.

Step 5. Calculate the normalized decision matrix $r_{i j}$ using the following formula:

$$
r_{i j}=\left\{\begin{array}{l}
\frac{x_{i j}}{\max \left(x_{j}\right)} \text { for positive criteria } \\
\frac{\min \left(x_{j}\right)}{x_{i j}} \text { for negative criteria }
\end{array}\right.
$$

where $i=1,2, \ldots, m ; j=1,2, \ldots, n, x_{j}$ is the value of attribute $x$ in column $j$, and $x_{i j}$ is the value of attribute $x$ in the row $i$ and column $j$.

Step 6. Compute the alternative preference value $V_{i}$ using the following formula:

$$
V_{i}=\sum_{j=1}^{n} w_{j} r_{i j}
$$


Through the SAW method, the alternative will be ranked by the sum of weighted values for all criteria. The preferred alternatives are indicated by the larger value of $V_{i}$. The defined value and weighted preference for alternatives in the SAW algorithm could generate the decision precisely.

\subsubsection{Technique for order preference by similarity to ideal solution (TOPSIS)}

The TOPSIS method is a method to select the best alternative, which is closest to the positive ideal solution and farthest to the negative ideal solution [21]. In decision making, the best alternative or the ideal solution is an alternative with a higher value and it can be used to make a decision. TOPSIS is commonly used because it has a simplicity to understand the concept, efficient in computation, and capability to measure the relative performance of decision alternatives on the simple mathematical form. The TOPSIS method is summarized in Algorithm 2, as follows.

\section{Algorithm 2: The TOPSIS algorithm}

Input: Performance ratings $r_{i j}$ for each alternative $A_{i}$ that are normalized on $C_{j}$, that is:

$$
r_{i j}=\frac{x_{i j}}{\sqrt{\sum_{i=1}^{m} x_{i j}^{2}}}
$$

Output: Alternative preference values $V_{i}$.

Step 1. Compute the normalized decision matrix for each alternative using weighted of each criterion:

$$
y_{i j}=w_{i} r_{i j}
$$

Step 2. Compute the highest value $A^{+}$as the ideal positive solution and the lowest value $A^{-}$ as the negative ideal solution, as follows:

$$
\begin{aligned}
& A^{+}=\left(y_{1}^{+}, y_{2}^{+}, \ldots, y_{m}^{+}\right) \\
& A^{-}=\left(y_{1}^{-}, y_{2}^{-}, \ldots, y_{m}^{-}\right)
\end{aligned}
$$

where $y_{j}^{+}$is the maximum of $y_{i j}$ if $j$ is the positive attribute, and $y_{j}^{+}$is the minimum of $y_{i j}$ if $j$ is the negative attribute, Otherwise, $y_{j}^{-}$is the minimum of $y_{i j}$ if $j$ is the negative attribute, and $y_{j}^{-}$is the maximum of $y_{i j}$ if $j$ is the positive attribute.
Step 3. Determine the distance of each alternative to the ideal positive solution $\left(D_{i}^{+}\right)$and negative ideal solution $\left(D_{i}^{-}\right)$.

$$
\begin{aligned}
& D_{i}^{+}=\sqrt{\sum_{i=1}^{n}\left(y_{i}^{+}-y_{i j}\right)^{2}} \\
& D_{i}^{-}=\sqrt{\sum_{i=1}^{n}\left(y_{i j}-y_{i}^{-}\right)^{2}}
\end{aligned}
$$

Step 4. Compute the alternative preference value $V_{i}$ using the following formula:

$$
V_{i}=\frac{D_{i}^{-}}{D_{i}^{-}+D_{i}^{+}}
$$

\subsubsection{The composite of SAW and TOPSIS}

As explained in Section 3.2, the student entrepreneurial potential rank in this study will be determined using the composite of the SAW and TOPSIS methods. This composite method is proposed based on the preliminary experiment on the SAW and TOPSIS methods in decision making. The SAW method has more precisely to generate the related alternatives based on the criteria and the level of important attributes. While the TOPSIS method has a good performance to select the best alternative solution by considering the positive and negative distances between the alternatives.

Based on these considerations above, this study proposes the composite of the SAW and TOPSIS methods to determine the student entrepreneurial potential rank, rather than using either the SAW only or the TOPSIS only. Technically, the SAW method is used to calculate the normalized decision matrix $r_{i j}$ related to Step 1 to Step 5 in Algorithm 1. Whereas, the chosen of the best alternative solution uses the TOPSIS method related to Algorithm 2.

\footnotetext{
Algorithm 3: The SAW-TOPSIS algorithm

Input: Value set $\left\{x_{1}, x_{2}, \ldots, x_{i}\right\}$ of alternative $A_{i}$.

Output: Alternative preference values $V_{i}$.

Step 1. Define alternatives $\left\{A_{1}, A_{2}, \ldots, A_{i}\right\}$.

Step 2. Define criteria for references in decision making $\left\{C_{1}, C_{2}, \ldots, C_{j}\right\}$.

Step 3. Define the rating of each alternative on each criterion.

Step 4. Define the weight or level of importance for each criterion $\left\{w_{1}, w_{2}, \ldots, w_{j}\right\}$.

Step 5. Compute the normalized decision matrix for each alternative using Eq. (7)

Step 6. Compute the highest value $A^{+}$as the ideal positive solution and the lowest value $A^{-}$
} 
as the negative ideal solution using Eq. (8) and Eq. (9), respectively.

Step 7. Determine the distance of each alternative to the ideal positive solution $\left(D_{i}^{+}\right)$and negative ideal solution $\left(D_{i}^{-}\right)$using Eq. (10) and Eq. (11), respectively.

Step 8. Compute the alternative preference value $V_{i}$ using Eq. (12).

\subsubsection{Creating the student entrepreneurial potential map}

The student entrepreneurial potential rank in this stage will produce the rank of students based on the level of intention in entrepreneurial behavior. The next stage is creating the student entrepreneurial potential map, which will be used to present the student entrepreneurial potential completely. This student entrepreneurial potential map can be used as the decision support system for university management to take the student entrepreneurial policy. In this study, the $k$ - means clustering method is applied to create the student entrepreneurial potential map though some related to the entrepreneurial intention clusters.

\section{Algorithm 4: The k-means clustering algorithm \\ Input: Value set $\left\{x_{1}, x_{2}, \ldots, x_{i}\right\}$ of alternative $A_{i}$ and the number of initial clusters $k$. \\ Output: A set of $k$ clusters. \\ Step 1. Choose $k$ data items from $\left\{x_{1}, x_{2}, \ldots, x_{i}\right\}$ as the initial centroids. \\ Step 2. Assign each item data $x$ to the cluster that has the closest centroid. \\ Step 3. Calculate new arithmetic mean for each cluster. \\ Step 4. Repeat step 2 and step 3 until satisfying the convergence criteria.}

The $k$ - means clustering is chosen as a part of the proposed method because this study uses five linguistic variables, which are very low, low, medium, high, and very high, which can be used as the initial cluster numbers. The brief of the $k$-means clustering method is performed using Algorithm 4.

\section{Results and discussion}

The objective of this study is mainly to create the student entrepreneurial potential map using the SAW-TOPSIS and $k$-means clustering methods based on the TPB model that is proposed in the previous section. The experimental of this study is
Table 4. Alternative, criteria, and weight of attribute

\begin{tabular}{|c|c|c|c|}
\hline Code & Alternative & Criteria & Weight \\
\hline A1 & Scholarship status & $\begin{array}{l}\text { Scholarship } \\
\text { Non- } \\
\text { scholarship }\end{array}$ & $\begin{array}{c}1 \\
0.25\end{array}$ \\
\hline $\mathrm{A} 2$ & Activist status & $\begin{array}{l}\text { Activist } \\
\text { Non-activist }\end{array}$ & $\begin{array}{c}1 \\
0.25\end{array}$ \\
\hline A3 & Type of entry & $\begin{array}{l}\text { Non-regular } \\
\text { AVG }>7 \\
\text { Regular test } \\
\text { Transfer } \\
\text { Moving }\end{array}$ & $\begin{array}{c}1 \\
0.75 \\
0.5 \\
0.25 \\
0\end{array}$ \\
\hline A4 & Parents occupation & $\begin{array}{l}\text { Entrepreneur } \\
\text { Non- } \\
\text { entrepreneur }\end{array}$ & $\begin{array}{c}1 \\
0.25\end{array}$ \\
\hline A5 & Parents income & $\begin{array}{l}>10 \text { million } \\
7-10 \text { million } \\
5-7 \text { million } \\
3-5 \text { million } \\
<3 \text { million } \\
\end{array}$ & $\begin{array}{c}1 \\
0.75 \\
0.5 \\
0.25 \\
0\end{array}$ \\
\hline A6 & GPA & $\begin{array}{l}\text { Cum laude } \\
\text { High } \\
\text { satisfactory } \\
\text { Satisfying } \\
\text { Good }\end{array}$ & $\begin{array}{c}1 \\
0.75 \\
0.5 \\
0.25\end{array}$ \\
\hline \multicolumn{4}{|c|}{ Course Score: } \\
\hline A7 & $\begin{array}{l}\text { Indonesian } \\
\text { language }\end{array}$ & \multirow{6}{*}{$\begin{array}{l}\mathrm{A} \\
\mathrm{B} \\
\mathrm{C} \\
\mathrm{D} \\
\mathrm{E}\end{array}$} & \multirow{6}{*}{$\begin{array}{c}1 \\
0.75 \\
0.5 \\
0.25 \\
0\end{array}$} \\
\hline A8 & English & & \\
\hline A9 & Research method & & \\
\hline A10 & Professional ethics & & \\
\hline A11 & Counseling & & \\
\hline A12 & Entrepreneurship & & \\
\hline A13 & $\begin{array}{l}\text { Business incubator } \\
\text { status }\end{array}$ & $\begin{array}{l}\text { Member } \\
\text { Non-member }\end{array}$ & $\begin{array}{c}1 \\
0.25\end{array}$ \\
\hline A14 & CSEP status & $\begin{array}{l}\text { Excellent } \\
\text { Funded } \\
\text { Proposing }\end{array}$ & $\begin{array}{c}1 \\
0.75 \\
0.5 \\
\end{array}$ \\
\hline
\end{tabular}

conducted and analyzed intensively to evaluate the proposed method. This study uses the Indonesia higher education database from 2009 to 2015 years as the experimental dataset based on the true status of the CSEP attribute. The CSEP attribute is a specific student attribute that represents the intention of students to join the student entrepreneurial program, which is offered by the government. There are 336 students with the true status of CSEP attributes, which are 273 in proposing status and 63 in funded status. The first stage in this experiment is defining the alternatives, criteria, and weight of each criterion associates with step 1 to step 3 in Algorithm 3. The results of these steps are summarized in Table 4.

There are 14 selected attributes from the higher education dataset related to the TPB beliefs that are 
Table 5. Compatibility rating of each alternative

\begin{tabular}{|c|c|c|c|c|c|c|c|c|c|c|c|c|c|l|}
\hline Instance & $\mathbf{A 1}$ & $\mathbf{A 2}$ & $\mathbf{A 3}$ & $\mathbf{A 4}$ & $\mathbf{A 5}$ & $\mathbf{A 6}$ & $\mathbf{A 7}$ & $\mathbf{A 8}$ & $\mathbf{A 9}$ & $\mathbf{A 1 0}$ & $\mathbf{A 1 1}$ & $\mathbf{A 1 2}$ & $\mathbf{A 1 3}$ & $\mathbf{A 1 4}$ \\
\hline 1 & 1 & 0.25 & 0.5 & 0.25 & 0.5 & 0.75 & 1 & 0.75 & 1 & 0.75 & 1 & 0.75 & 0.25 & 0.5 \\
\hline 2 & 1 & 0.25 & 0.5 & 1 & 0.75 & 0.5 & 1 & 0.75 & 0.75 & 1 & 1 & 0.75 & 1 & 0.5 \\
\hline 3 & 0.25 & 0.25 & 0.5 & 1 & 0.25 & 0.5 & 1 & 0.5 & 0.75 & 1 & 1 & 0.75 & 1 & 0.75 \\
\hline 4 & 1 & 0.25 & 0.5 & 0.25 & 0.75 & 0.5 & 0.75 & 0.5 & 0.75 & 0.75 & 1 & 1 & 0.25 & 0.5 \\
\hline$\ldots$ & $\ldots$ & $\ldots$ & $\ldots$ & $\ldots$ & $\ldots$ & $\ldots$ & $\ldots$ & $\ldots$ & $\ldots$ & $\ldots$ & $\ldots$ & $\ldots$ & $\ldots$ & $\ldots$ \\
\hline 333 & 1 & 1 & 0.5 & 0.25 & 0 & 1 & 1 & 0.75 & 0.75 & 0.5 & 0.75 & 1 & 0.25 & 0.5 \\
\hline 334 & 0.25 & 0.25 & 0.5 & 0.25 & 0 & 0.25 & 0.75 & 0.75 & 0.75 & 0.5 & 0.75 & 0.75 & 0.25 & 0.5 \\
\hline 335 & 0.25 & 0.25 & 0.5 & 1 & 0.75 & 0.75 & 0.75 & 0.75 & 1 & 0.5 & 1 & 1 & 0.25 & 0.5 \\
\hline 336 & 0.25 & 0.25 & 0.5 & 1 & 0.5 & 0.75 & 0.5 & 0.75 & 1 & 0.5 & 0.75 & 0.75 & 1 & 0.5 \\
\hline
\end{tabular}

attitude, subjective norms, and perceived behavioral control as described in Table 1. Each attribute will be used as an alternative solution for decision making. To apply the SAW-TOPSIS method, the criteria of each alternative are defined from the dataset. Besides, the weights of criteria are defined using the fuzzy membership function. The criterion weighting is done through manual analysis with the university management. As shown in Table 4, there is a one-to-one relationship between the criteria and its weight to achieve the certain data value of attributes and to address the fuzziness of the dataset.

The selected variable from the Indonesia higher education database is relevant because it is similar to the individual attributes in the Global Entrepreneurship Monitor (GEM) dataset which are indicators of demographic characteristics (gender, age, etc.), self-perception (capability perception, perception of opportunity, fear of failure) and motivation to start a business [15]. Following the entrepreneurship process model developed by GEM, the first step is to grow potential entrepreneurs by providing business opportunities and providing adequate knowledge and skills. The TPB studies on entrepreneurship in the student environment prove that attitude, subjective norms and perceived behavioral control $[3,25]$, which is integrated with entrepreneurship education would be able to have a positive and significant influence on the increasing entrepreneurial intentions of students and creating entrepreneurial behavior [27-31].

The next step is defining the weight or level of importance for each criterion associated with step 4 in Algorithm 2. This step requires the compatibility rating of each alternative, as defined in Table 5 . Using Table 4, Table 5, and the fuzzy number in Table 3, the decision matrix can be obtained using Eq. (3) that gives the result as follows.

$$
r_{i j}=\left(\begin{array}{ccccccccc}
1 & 0.25 & 0.5 & 0.25 & \cdots & 1 & 0.75 & 0.25 & 0.5 \\
1 & 0.25 & 0.5 & 0.25 & \cdots & 1 & 0.75 & 1 & 0.5 \\
0.25 & 0.25 & 0.5 & 1 & \cdots & 1 & 0.75 & 1 & 0.75 \\
1 & 0.25 & 0.5 & 1 & \cdots & 1 & 1 & 0.25 & 0.5 \\
\cdots & \cdots & \cdots & \cdots & \cdots & \cdots & \cdots & \cdots & \cdots \\
1 & 1 & 0.5 & 0.25 & \cdots & 0.75 & 1 & 0.25 & 0.5 \\
0.25 & 0.25 & 0.5 & 0.25 & \cdots & 0.75 & 0.75 & 0.25 & 0.5 \\
0.25 & 0.25 & 0.5 & 1 & \cdots & 1 & 1 & 0.25 & 0.5 \\
0.25 & 0.25 & 0.5 & 1 & \cdots & 0.75 & 0.75 & 0.25 & 0.5
\end{array}\right)
$$

This decision matrix gives the preference weight for each criterion, so the generated weight vector is: $w_{j}$ $=[1,1,0.75,0.75,0.25,0.25,0.50,0.25,0.50,0.25$, $0.25,0.25,0.75,0.75]$. The normalized decision matrix for each alternative related to step 5 in Algorithm 3 is then computed using Eq. (6), which gives the result as follows.

$$
\begin{aligned}
& y_{i j} \\
& =\left(\begin{array}{ccccccccc}
1 & 0.25 & 0.375 & 0.1875 & \cdots & 0.25 & 0.375 & 0.1875 & 0.375 \\
1 & 0.25 & 0.375 & 0.75 & \cdots & 0.25 & 0.375 & 0.75 & 0.375 \\
0.25 & 0.25 & 0.375 & 0.75 & \cdots & 0.25 & 0.375 & 0.75 & 0.5625 \\
1 & 0.25 & 0.375 & 0.1875 & \cdots & 0.25 & 0.5 & 0.1875 & 0.375 \\
\cdots & \cdots & \cdots & \cdots & \cdots & \cdots & \cdots & \cdots & \cdots \\
1 & 1 & 0.375 & 0.1875 & \cdots & 0.1875 & 0.5 & 0.1875 & 0.375 \\
0.25 & 0.25 & 0.375 & 0.1875 & \cdots & 0.1875 & 0.375 & 0.1875 & 0.375 \\
0.25 & 0.25 & 0.375 & 0.75 & \cdots & 0.25 & 0.5 & 0.1875 & 0.375 \\
0.25 & 0.25 & 0.375 & 0.75 & \cdots & 0.1875 & 0.375 & 0.75 & 0.375
\end{array}\right)
\end{aligned}
$$

The matrix $y_{i j}$ leads the $y_{j}^{+}$and $y_{j}^{-}$values that are obtained using Eq. (7) and Eq. (8), respectively, which are presented in Table 6 . The next step is determining the distance of alternative toward a positive and negative ideal solution using Eq. (9) and Eq. (10) associated with step 7 in Algorithm 3. The results of this step are presented in Table 7 , where all of the values are obtained by moving and arranging both the max and the min values. The last step of applying the SAW-TOPSIS method is finding the preference value of each alternative using Eq. (11). This step is associated with step 8 in Algorithm 3. The results of the preference value $V_{i}$ are presented in Table 8 . While the preference value rank based on the ordered preference value is presented in Table 9. 
Table 6. A positive and negative ideal solution

\begin{tabular}{|c|c|c|c|}
\hline \multicolumn{2}{|c|}{ Positive Ideal Solution } & \multicolumn{2}{c|}{ Negative Ideal Solution } \\
\hline Code & Score & Code & Score \\
\hline $\mathrm{y} 1+$ & 0.5000 & $\mathrm{y} 1-$ & 0.1250 \\
\hline $\mathrm{y} 2+$ & 1.0000 & $\mathrm{y} 2-$ & 0.2500 \\
\hline $\mathrm{y} 3+$ & 1.0000 & $\mathrm{y} 3-$ & 0.2500 \\
\hline $\mathrm{y} 4+$ & 0.7500 & $\mathrm{y} 4-$ & 0.0000 \\
\hline $\mathrm{y} 5+$ & 0.7500 & $\mathrm{y} 5-$ & 0.1875 \\
\hline $\mathrm{y} 6+$ & 0.2500 & $\mathrm{y} 6-$ & 0.0000 \\
\hline $\mathrm{y} 7+$ & 0.2500 & $\mathrm{y} 7-$ & 0.0000 \\
\hline $\mathrm{y} 8+$ & 0.2500 & $\mathrm{y} 8-$ & 0.0000 \\
\hline $\mathrm{y} 9+$ & 0.5000 & $\mathrm{y} 9-$ & 0.0000 \\
\hline $\mathrm{y} 10+$ & 0.2500 & $\mathrm{y} 10-$ & 0.1250 \\
\hline $\mathrm{y} 11+$ & 0.2500 & $\mathrm{y} 11-$ & 0.0000 \\
\hline $\mathrm{y} 12+$ & 0.5000 & $\mathrm{y} 12-$ & 0.2500 \\
\hline $\mathrm{y} 13+$ & 0.7500 & $\mathrm{y} 13-$ & 0.1875 \\
\hline $\mathrm{y} 14+$ & 0.7500 & $\mathrm{y} 14-$ & 0.0000 \\
\hline
\end{tabular}

Table 7. Alternative distance toward the positive and negative ideal solution

\begin{tabular}{|c|c|c|c|}
\hline \multicolumn{2}{|c|}{ Positive Ideal Solution } & \multicolumn{2}{c|}{ Negative Ideal Solution } \\
\hline Code & Score & Code & Score \\
\hline $\mathrm{D}_{1}{ }^{+}$ & 1.2339 & $\mathrm{D}_{1}{ }^{-}$ & 2.0584 \\
\hline $\mathrm{D}_{2}{ }^{+}$ & 0.9703 & $\mathrm{D}_{2}{ }^{-}$ & 2.2930 \\
\hline $\mathrm{D}_{3}{ }^{+}$ & 1.1991 & $\mathrm{D}_{3}{ }^{-}$ & 2.1133 \\
\hline $\mathrm{D}_{4}{ }^{+}$ & 1.2562 & $\mathrm{D}_{4}{ }^{-}$ & 2.0175 \\
\hline--- & --- & --- & --- \\
\hline $\mathrm{D}_{333}{ }^{+}$ & 1.0078 & $\mathrm{D}_{333^{-}}$ & 2.1955 \\
\hline $\mathrm{D}_{334^{+}}$ & 1.5168 & $\mathrm{D}_{334^{-}}$ & 1.6607 \\
\hline $\mathrm{D}_{335^{+}}$ & 1.3273 & $\mathrm{D}_{335^{-}}$ & 2.0329 \\
\hline $\mathrm{D}_{336^{+}}$ & 1.2180 & $\mathrm{D}_{336^{-}}$ & 2.0885 \\
\hline
\end{tabular}

The student entrepreneurial potential selection has been performed using the composite SAW-TOPSIS based on the FMADM approach. The most potential students can be selected through the preference values rank in Table 9. To address the limitation of organization resources, university management can select a certain number of the top potential students to implement the student entrepreneurial program. This student selection can be used as part of the decision making in the student entrepreneurial policy.

Table 8. Preference values of all instance

\begin{tabular}{|c|c|}
\hline Code & Values \\
\hline $\mathrm{V}_{1}$ & 0.6252 \\
\hline $\mathrm{V}_{2}$ & 0.7027 \\
\hline $\mathrm{V}_{3}$ & 0.6380 \\
\hline $\mathrm{V}_{4}$ & 0.6163 \\
\hline--- & --- \\
\hline $\mathrm{V}_{333}$ & 0.6854 \\
\hline $\mathrm{V}_{334}$ & 0.5226 \\
\hline $\mathrm{V}_{335}$ & 0.6050 \\
\hline $\mathrm{V}_{336}$ & 0.6316 \\
\hline
\end{tabular}

Table 9. Preference values rank of all instance

\begin{tabular}{|c|c|c|}
\hline Instance & Rank & Values \\
\hline 60 & 1 & 0.8619 \\
\hline 129 & 2 & 0.8277 \\
\hline 230 & 3 & 0.8216 \\
\hline 130 & 4 & 0.8116 \\
\hline--- & --- & --- \\
\hline 275 & 333 & 0.5088 \\
\hline 249 & 334 & 0.5088 \\
\hline 254 & 335 & 0.5064 \\
\hline 253 & 336 & 0.4937 \\
\hline
\end{tabular}

Table 10. Data distribution of successful students in the CSEP participation

\begin{tabular}{|l|c|c|c|}
\hline $\begin{array}{l}\text { Potential } \\
\text { Level }\end{array}$ & $\begin{array}{c}\text { Total of } \\
\text { Students }\end{array}$ & $\begin{array}{c}\text { Total of } \\
\text { Success }\end{array}$ & $\begin{array}{c}\text { Percentage } \\
(\%)\end{array}$ \\
\hline Medium & 178 & 23 & 13 \\
\hline High & 148 & 34 & 23 \\
\hline Very High & 10 & 6 & 60 \\
\hline Total & $\mathbf{3 3 6}$ & $\mathbf{6 3}$ & \\
\hline
\end{tabular}

\section{Relationship Level of Entrepreneurship Potential With CSEP Achievement}

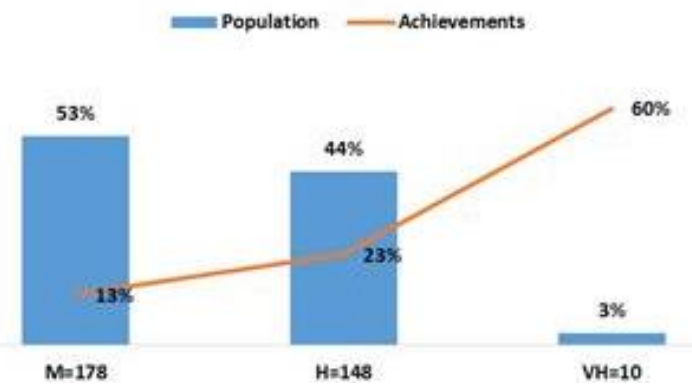

Figure. 5 Relationship level of entrepreneurial potential

The student entrepreneurial potential in Table 9 is then categorized into the medium, high dan very high three potential levels based on the $V_{i}$ range of values, which are defined as follows:

a. Medium (M) level for $0.4937 \leq V_{i} \leq 0.6164$;

b. High $(\mathrm{H})$ level for $0.6165 \leq V_{i} \leq 0.7392$;

c. Very high $(\mathrm{VH})$ level for $0.7393 \leq V_{i} \leq 0.8620$. The length of each level is defined using the length $=\left\{\max \left(V_{i}\right)-\min \left(V_{i}\right)\right\} / k$ with $k$ is the number of level classes. Based on the $V_{i}$ values in Tabel 9, the length of each level class is 0.1228 . The data distribution of the student entrepreneurial potential who are successful to obtain the CSEP to the total students is shown in Table 10.

The relationship between the entrepreneurial potential level with CSEP achievement is illustrated in Fig. 5. It shows that the entrepreneurial potential level is inversely potential to the sum of the students. The higher entrepreneurial potential level only followed by a smaller number of students. However, the chance of students to gain the CSEP is getting higher. In other words, the student entrepreneurial potential level is equivalent to the CSEP achievement. Hence, the composite SAW-TOPSIS method is feasible to be used as the student entrepreneurial potential reference.

Finally, to complete the representation of the student entrepreneurial behavior, the $k$ - means clustering is applied to group the potential students into the student entrepreneurial behavior map. The clustering process using the $k$-means clustering produces the optimal student groups in the four clusters based on the predefined linguistic variables. 


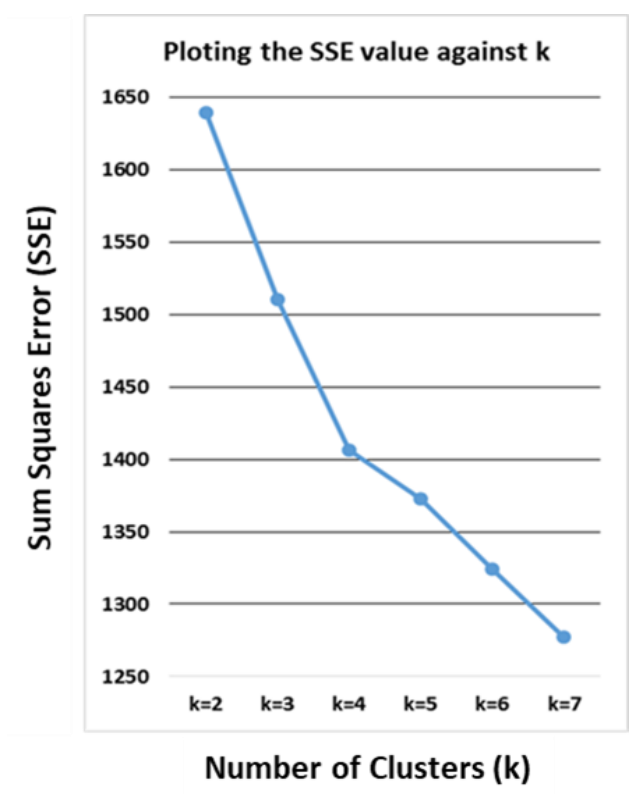

Figure. 6 Plotting SSE

The clustering experiment was conducted to cluster 2's to 7's size with a random seed $s=10$. The clustering results for each combination $k$ and $s$ were evaluated by a sum of squares error (SSE) total. The SSE total is sufficient to evaluate clusters since it minimizes equivalent SSE by maximizing the sum of squares between (SSB) clusters.

Fig. 6 shows the plotting of the SSE total value for each $k$. The SSE value is decreasing as the cluster size is increasing. It is synchronous with $k$-means algorithm characteristic.

On the SSE total criteria, the best clustering distance will select total clusters as many as an object [36]. The number of cluster characteristics could be found within the experimental data by looking at the cluster size as knee, peak, or dip within plot graphic of evaluation scale to cluster size are found [37]. As shown in Fig. 6, the distinct knee of the clusters is on the $k=4$, so it can be concluded that the best number of clusters in this study is about 4 clusters or $k=4$, namely cls $0, c l s 1, c l s 2$, and $c l s 4$.

The summary of the clustering results is described in Table 11, which can be discussed as follows:

a. Cluster $\operatorname{cls} 0$ is produced using the centroids of many criteria values, which are: $\mathrm{A} 1=$ 'notscholarship', A2='not-activists', A3='AVG $>7.0$ ', A4='not-entrepreneurs', A5='less than 3 million', A6='satisfying', A7='B', A8='B', A9='A', $\mathrm{A} 10={ }^{\prime} \mathrm{C}^{\prime}, \mathrm{A} 11={ }^{\prime} \mathrm{A}$ ', $\mathrm{A} 12={ }^{\prime} \mathrm{A}$ ', A13='member', and A14='proposing'. The centroid score of this cluster is 0.5485 , hence this cluster can be categorized as a cluster with a medium level of entrepreneurial potential. In the attitude belief, the members of this cluster do not have a standout attitude belief (not-scholarship and not activist) and originated from a non-test registration path $(A V G>7)$. In the subjective norms belief, the members of this cluster possess satisfying academic achievement and come from a non-entrepreneurs family with less than 3 million monthly incomes. In the perceived behavior control belief, the members of this cluster have positive perception toward entrepreneurship because they are a member of a business incubator program.

Table 11. Summary of the student entrepreneurial potential

\begin{tabular}{|c|c|c|c|c|}
\hline $\begin{array}{l}\text { Clu } \\
\text { ster }\end{array}$ & $\begin{array}{l}\text { Insta } \\
\text { nces }\end{array}$ & $\begin{array}{l}\text { Centroid } \\
\text { Attributes }\end{array}$ & $\begin{array}{c}\text { Centro } \\
\text { id } \\
\text { Scores }\end{array}$ & $\begin{array}{c}\text { Potenti } \\
\text { al } \\
\text { Level }\end{array}$ \\
\hline cls0 & 114 & $\begin{array}{l}\text { Not-scholarship, } \\
\text { not-activists, } \\
\text { AVG > 7.0, not- } \\
\text { entrepreneurs, } \\
\text { less than } 3 \\
\text { million, } \\
\text { satisfying, B, B, } \\
\text { A, C, A, A, } \\
\text { member, } \\
\text { proposing }\end{array}$ & 0.5485 & $\begin{array}{c}\text { Mediu } \\
\mathrm{m}\end{array}$ \\
\hline cls1 & 132 & $\begin{array}{l}\text { Scholarship, non- } \\
\text { activists, regular } \\
\text { test, not- } \\
\text { entrepreneurs, 3-5 } \\
\text { million, highly } \\
\text { satisfactory, A, B, } \\
\text { B, C, A, A, non- } \\
\text { member, } \\
\text { proposing }\end{array}$ & 0.6186 & High \\
\hline cls2 & 36 & $\begin{array}{l}\text { Scholarship, } \\
\text { activists, regular, } \\
\text { not-entrepreneurs, } \\
5-7 \text { million, cum } \\
\text { laude, A, B, } \\
\text { A, C, A, A, } \\
\text { member, } \\
\text { proposing }\end{array}$ & 0.7520 & $\begin{array}{l}\text { Very } \\
\text { High }\end{array}$ \\
\hline cls3 & 54 & $\begin{array}{l}\text { Not-scholarship, } \\
\text { activists, non- } \\
\text { regular selection, } \\
\text { not-entrepreneurs, } \\
\text { 3-5 million, } \\
\text { highly } \\
\text { satisfactory, B, B, } \\
\text { B, C, A, A, } \\
\text { member, } \\
\text { proposing }\end{array}$ & 0.6798 & High \\
\hline
\end{tabular}


b. Cluster $c l s 1$ is produced using the centroids of many criteria values, which are: A1='scholarship', $\quad$ A2='non-activist', A3='regular test', A4='not entrepreneurs', A5='3-5 million', A6='highly satisfactory', $\mathrm{A} 7={ }^{\prime} \mathrm{A}$ ', $\mathrm{A} 8$ ='B', A9='B', A10='C', A11='A', $\mathrm{A} 12={ }^{\prime} \mathrm{A}$ ', $\mathrm{A} 13=$ 'non-member', $\quad$ and A14='proposing'. The centroid score of this cluster is 0.5485 , hence this cluster can be categorized as a cluster with a high level of entrepreneurial potential. In the attitude belief, the members of this cluster have a good academic attitude by becoming a scholarship grantee and are originated from a regular registration path. In the subjective norms belief, the members of this cluster have a highly satisfactory academic achievement and come from a non-entrepreneurs family with 3-5 million monthly incomes. However, the members of this cluster have a negative perception control toward entrepreneurship since they are not a member of a business incubator program.

c. Cluster cls 2 is produced using the centroid of many criteria values, which are: A1='scholarship', A2='activists', A3='regular test', $\mathrm{A} 4=$ ='not-entrepreneurs', $\mathrm{A} 5=$ ='5-7 million', A6='cumlaude', A7='A', A8='B', A9='A', $\mathrm{A} 10={ }^{\prime} \mathrm{C}$ ', $\mathrm{A} 11={ }^{\prime} \mathrm{A}$ ', A12='A', A13='member', and $\mathrm{A} 14=$ 'proposing'. This cluster has 0.7520 of the centroid score, hence the cluster $\mathrm{C} 2$ can be categorized as a cluster with a very high entrepreneurial potential. In the attitude belief, the members of this cluster have attitude characteristics that are academic attitude as the scholarship grantee, non-academic one as activists, and originated from the regular registration path. In the subjective norms belief, the members of this cluster have normative characteristics that are cum laude academic achievement and come from a non-entrepreneurs family with 5-7 million monthly incomes. In the perceived behavior control, the members of this cluster have positive perception because they are a member of a business incubator program.

d. Cluster cls3 is produced using the centroids of many criteria values, which are: $\mathrm{A} 1=$ 'notscholarship', A2='activist', A3='non-regular test selection', A4='not-entrepreneurs', A5='3-5 million', $\mathrm{A} 6=$ 'highly satisfactory', $\mathrm{A} 7={ }^{\prime} \mathrm{B}$ ', $\mathrm{A} 8={ }^{\prime} \mathrm{B}$ ', $\mathrm{A} 9={ }^{\prime} \mathrm{B}$ ', $\mathrm{A} 10={ }^{\prime} \mathrm{C}^{\prime}, \mathrm{A} 11={ }^{\prime} \mathrm{A}$ ', A12='A', $\mathrm{A} 13=$ 'member', and A14='proposing'. This cluster has 0.6798 of the centroid score, hence this cluster is categorized as a cluster with high entrepreneurial potential. In the attitude belief, the members of this cluster have a good non- academic attitude by becoming activists and are originated from the non-regular selection path. In the subjective norms belief, the members of this cluster have a highly satisfactory academic achievement and come from a non-entrepreneurs family with 3-5 million monthly incomes. In the perceived behavior control, the members of this cluster have positive perception because they are a member of a business incubator program.

Some insightful knowledge could be exposed to the clustering results. There are two clusters with a high potential level, which are cluster $c l s 1$ with the centroid score of 0.6186 and cluster cls 3 with the centroid score of 0.6798 . The interesting part of these results is that the centroid score gap between the cluster cls 1 (high level) and the cluster cls 0 (medium level) is near to the centroid score gap of the cluster cls3 (high level) and the cluster cls2 (very high level), which is approximately about 0.07 . Based on the observation, this distinction is influenced by two prominent beliefs that are attitude belief with scholarship status, activist status attributes, and the perceived behavior control belief with the business incubator status attribute.

Related to the CSEP, the achievement of each cluster and their respective entrepreneurial potential level is illustrated in Fig. 7, which are described as follows.

a. As many as $19 \%$ of members in the $c l s 0$ cluster (medium level) have the optimum achievement on the CSEP, which are contributed by the medium and high potential levels of $68 \%$ and $32 \%$, respectively.

b. As many as $12 \%$ of members in the cls 1 cluster (high level) have the optimum achievement on the CSEP, which are contributed by the medium, high and very high potential levels of $19 \%, 69 \%$, and $12 \%$, respectively.

c. As many as $39 \%$ of members in the $c l s 2$ cluster (very high level) have the optimum achievement on the CSEP, which are contributed by the high and very high potential levels of $50 \%$ and $50 \%$, respectively.

d. As many as $20 \%$ of members in the cls 3 cluster (high level) have the optimum achievement on the CSEP, which are contributed by the medium and high potential levels of $18 \%$ and $82 \%$, respectively.

Based on the two high potential level clusters, it can be seen that the cls3 cluster has better achievement than the $c l s 1$ cluster. The $c l s 3$ cluster itself has a closer centroid score to the cls 2 cluster (very high level), while the $c l s 1$ cluster has a closer centroid score to the $c l s 0$ cluster (medium level). 
Comparison of Cluster Achievements and The Contribution of Each Potential Level

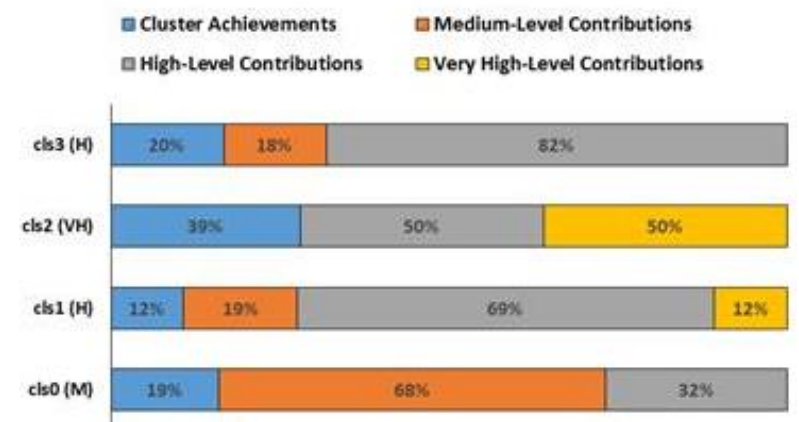

Figure. 7 Comparison of cluster achievements and the contribution of each potential level

Table 12. Approaches comparison of entrepreneurship analysis study

\begin{tabular}{|c|c|c|c|c|c|c|}
\hline \multirow{2}{*}{ Ref. } & \multicolumn{7}{|c|}{ Approaches } \\
\cline { 2 - 7 } & $\begin{array}{c}\text { MAD } \\
\text { M }\end{array}$ & Fuzzy & $\begin{array}{c}\text { Statis } \\
\text { tics }\end{array}$ & $\begin{array}{c}\text { Cluster } \\
\text { ing }\end{array}$ & $\begin{array}{c}\text { Oth } \\
\text { er }\end{array}$ & $\begin{array}{c}\text { TP } \\
\text { B }\end{array}$ \\
\hline$[8]$ & $\sqrt{ }$ & - & - & $\sqrt{ }$ & - & - \\
\hline$[9]$ & $\sqrt{ }$ & $\sqrt{ }$ & - & $\sqrt{ }$ & - & - \\
\hline$[15]$ & - & $\sqrt{ }$ & - & - & - & $\sqrt{ }$ \\
\hline$[23]$ & - & - & - & - & $\sqrt{ }$ & $\sqrt{ }$ \\
\hline$[25]$ & - & - & $\sqrt{ }$ & - & - & $\sqrt{ }$ \\
\hline$[26]$ & - & - & $\sqrt{ }$ & - & - & $\sqrt{ }$ \\
\hline$[32]$ & - & - & $\sqrt{ }$ & - & - & $\sqrt{ }$ \\
\hline $\begin{array}{c}\text { This } \\
\text { study }\end{array}$ & $\sqrt{ }$ & $\sqrt{ }$ & - & $\sqrt{ }$ & - & $\sqrt{ }$ \\
\hline
\end{tabular}

Hence, it can be concluded that the two attributes of attitude belief, which are scholarship status and activist status, and the one attribute of perceived behavior control, which is business incubator status, possess a significant influence on the enhancement of the CSEP achievement.

Overall, the results of this study could be expected to improve the preliminary studies in the student entrepreneurial potential mapping. In the early study, the student entrepreneurial potential mapping has been identified through a combination of the simple multi-attribute rating technique and clustering methods [8]. However, that study does not consider the student behavior to select the related attributes. The use of TPB in this study could affect the potential level of cluster results, which has been produced by the multi-attribute rating technique and clustering methods. The distinction approaches used in this study compared to the other studies are summarized in Table 12.

Table 12 shows that this study does not only apply the TPB approach for certain beliefs analysis in the student entrepreneurial intention. However, this study also utilizes the fuzzy, MADM and clustering approaches to produce the student entrepreneurial potential mapping to support the university management for decision making.

\section{Conclusions}

The student entrepreneurial potential mapping using the integration of SAW-TOPSIS decision making and clustering models have been presented in this study. Experimental results show that the integration of the fuzzy SAW-TOPSIS and clustering method based on the TPB is suitable to evaluate the student entrepreneurial potential. The proposed method could recognize the relevant attributes of students that are required for university management to support decision making in the student entrepreneurial program policies.

This study also yields four identified clusters to present the student entrepreneurial potential levels. The first cluster consists of $19 \%$ of CSEP achievement students who have medium and high potential levels of $68 \%$ and $32 \%$, respectively. The second cluster consists of $12 \%$ of CSEP achievement students who have medium, high and very high potential levels of $19 \%, 69 \%$, and $12 \%$, respectively. The third cluster consists of $39 \%$ of CSEP achievement students who have high and very high potential levels of $50 \%$ and $50 \%$, respectively. While the fourth cluster consists of $20 \%$ of CSEP achievement students who have medium and high potential levels of $18 \%$ and $82 \%$, respectively.

One of the important findings in this experiment is that the CSEP has a significant impact on the success of the student entrepreneurial program. The students who have funded in the CSEP will have a high chance to be an actual entrepreneur in the future. Besides, the students of CSEP have also a better attitude, subjective norms, and perceived behavior control beliefs rather than regular students.

For future work, the results of this study can be used as the initial points to identify and develop logical rules based on the student entrepreneurial potential mapping.

\section{Conflicts of Interest}

The authors declare no conflict of interest.

\section{Author Contributions}

Conceptualization, N. Rijati; methodology, N. Rijati, and D. Purwitasari; software, N. Rijati; validation, N. Rijati, D. Purwitasari, S. Sumpeno, and M.H. Purnomo; formal analysis, N. Rijati, D. Purwitasari, S. Sumpeno, and M.H. Purnomo; investigation, N. Rijati, D. Purwitasari, S. Sumpeno, and M.H. Purnomo; resources, N. Rijati, and D. 
Purwitasari; data curation, N. Rijati, and D. Purwitasari; writing - original draft preparation, N. Rijati; writing - review and editing, N. Rijati, and D. Purwitasari; visualization, N. Rijati; supervision, S. Sumpeno, and M.H. Purnomo; project administration, N. Rijati. All authors read and approved the final manuscript.

\section{Acknowledgments}

This work is supported by the Faculty of Computer Science at Universitas Dian Nuswantoro Semarang and the research group of Multimedia Computational Laboratory at Institut Teknologi Sepuluh Nopember Surabaya.

\section{References}

[1] T. W. Zimmerer and N. M. Scarborough, Essentials of Entrepreneurship and Small Business Management, 5th Edition, PrenticeHall, 2007.

[2] I. Ajzen, "The Theory of Planned Behavior", Organization Behavior and Human Decision Process, Vol. 50, Issue 2, pp. 179-211, 1991.

[3] S. Karimi, H. J. A. Biemans, K. N. Mahdei, T. Lans, M. Chizari, and M. Mulder, "Testing the Relationship Between Personality Characteristics, Contextual Factors and Entrepreneurial Intentions in a Developing Country", International Journal of Psychology, Vol. 52, No. 3, pp. 227-240, 2017.

[4] I. Joseph, "Factors Influencing International Student Entrepreneurial Intention in Malaysia", Research Journal of Business Management, Vol. 7, No. 4, pp. 424-428, 2017.

[5] $\mathrm{S}$. $\mathrm{Wu}$ and $\mathrm{L}$. $\mathrm{Wu}$, "The Impact of Higher Education on Entrepreneurial Intentions of University Students in China", Journal of Small Business and Enterprise Development, Vol. 15, No. 4, pp. 752-774, 2008.

[6] A. V. Mateu, ClusDM: A Multiple Criteria Decision Making Method for Heterogeneous Data Sets, Universitat Politecnica de Catalunya, 2003.

[7] C. Chen and C. M. Klein, "An Efficient Approach to Solving Fuzzy MADM Problems", Fuzzy Sets and Systems, Vol. 18, No. 1, pp. 5167, 1997.

[8] N. Rijati, S. Sumpeno, and M. H. Purnomo, "Multi-attribute Clustering of Student's Entrepreneurial Potential Mapping Based on Its Characteristics and the Affecting Factors (Preliminary Study on Indonesian Higher Education Database)", In: Proc. of International Conf. Computer and Automation
Engineering (ICCAE 2018), Brisbane, Australia, pp. 11-16, 2018.

[9] H. Güçdemir and H. Selim, "Integrating MultiCriteria Decision Making and Clustering for Business Customer Segmentation", Industrial Management and Data System, Vol. 115, No. 6, pp. 1022-1040, 2015.

[10] G. Kou, Y. Peng, and G. Wang, "Evaluation of Clustering Algorithms for Financial Risk Analysis using MCDM Methods", Information Sciences, Vol. 275, pp. 1-12, 2014.

[11] B. Rouba and S. N. Bahloul, "A Multicriteria Clustering Approach Based on Similarity Indices and Clustering Ensemble Techniques", International Journal of Information Technology \& Decision Making, Vol. 13, No. 04, pp. 811-837, 2014.

[12] S.-T. Wang, "An Analysis of the Optimal Customer Clusters using Dynamic MultiObjective Decision", International Journal of Information Technology \& Decision Making, Vol. 17, No. 2, pp. 547-582, 2018.

[13] S. M. H. Hojjati, and A. Anvary, "An Integrated MCDM Method in Ranking The Major Lean Practices Based on Four Attributes", World Applied Sciences Journal, Vol. 28, No. 11, pp. 1862-1871, 2013.

[14] P. Wang, Z. Zhu, and Y. Wang, "A Novel Hybrid MCDM Model Combining the SAW, TOPSIS and GRA Methods Based on Experimental Design", Information Sciences, Vol. 345, pp. 27-45, 2016.

[15] I. Khefacha and L. Belkacem, "Modeling Entrepreneurial Decision Making Process using Concepts from Fuzzy Set Theory", Journal of Global Entrepreneurship Research, Vol. 5, pp. 1-13, 2015.

[16] M. Fishbein and I. Ajzen, Belief, Attitude, Intention, and Behavior: An Introduction to Theory and Research, Reading, MA: AddisonWesley, 1975.

[17] I. Ajzen, Attitudes, Personality, and Behaviour, Open University Press, 2005.

[18] G. A. M. S. Wimatsari, I. K. G. D. Putra, and P. W. Buana, "Multi-attribute Decision Making Scholarship Selection using a Modified Fuzzy TOPSIS", International Journal of Computer Science Issues, Vol. 10, Issue 1, No. 2, pp. 309-317, 2013.

[19] W. Deni, O. Sudana, and A. Sasmita, "Analysis and Implementation Fuzzy Multi-Attribute Decision Making SAW Method for Selection of High Achieving Students in Faculty Level", International Journal of Computer Science 
Issues, Vol. 10, Issue 1, No. 2, pp. 674-680, 2013.

[20] R. Umar, Sunardi, and Y. B. Fitriana, "Taxonomy of Fuzzy Multi-Attribute Decision Making Systems in Terms of Model, Inventor and Data Type", Engineering, Technology \& Applied Science Research, Vol. 8, No. 1, pp. 2568-2571, 2018.

[21] I. Kaliszewski and D. Podkopaev, "Simple Additive Weighting - A Metamodel for Multiple Criteria Decision Analysis Methods", Expert Systems with Applications, Vol. 54, pp. 155-161, 2016.

[22] Y. Melia, "Multi-Attribute Decision Making using Simple Additive Weighting and Weighted Product in Investment Introduction", International Academic Journal of Business Management, Vol. 3, Issue 2, pp. 58-72, 2016.

[23] J. Lortie and G. Castogiovanni, "The Theory of Planned Behavior in Entrepreneurship Research: What We Know and Future Directions", International Entrepreneurship and Management Journal, Vol. 11, pp. 935957, 2015.

[24] W. J. Aloulou, "Predicting Entrepreneurial Intentions of Final Year Saudi University Business Students by Applying the Theory of Planned Behavior", Journal of Small Business and Enterprise Development, Vol. 23, No. 4, pp. 1142-1164, 2016.

[25] C. W. Utami, "Attitude, Subjective Norms, Perceived Behavior, Entrepreneurship Education and Self-Efficacy Toward Entrepreneurial Intention University Student in Indonesia", European Research Studies Journal, Vol. 20, Issue 2A, pp. 475-495, 2017.

[26] A. Heuer and L. Kolvereid, "Education in Entrepreneurship and the Theory of Planned Behaviour", European Journal of Training and Development, Vol. 38, No. 6, pp. 506-523, 2014.

[27] F. Liñán and A. Fayolle, "A Systematic Literature Review on Entrepreneurial Intentions: Citation, Thematic Analyses, and Research Agenda", International Entrepreneurship and Management Journal, Vol. 11, pp. 907-933, 2015.

[28] D. Maresch, R. Harms, N. Kailer, and B. Wimmer-Wurm, "The Impact of Entrepreneurship Education on the Entrepreneurial Intention of Students in Science and Engineering Versus Business Studies University Programs," Technological Forecasting and Social Change, Vol. 104, pp. 172-179, 2016.
[29] H. Sun, C. T. Lo, B. Liang, and Y. L. B. Wong, "The Impact of Entrepreneurial Education on Entrepreneurial Intention of Engineering Students in Hong Kong", Management Decision, Vol. 55, No. 7, pp. 1371-1393, 2017.

[30] M. Küttim, M. Kallaste, U. Venesaar, and A. Kiis, "Entrepreneurship Education at University Level and Students'entrepreneurial Intentions", Procedia - Social and Behavioral Sciences, Vol. 110, pp. 658-668, 2014.

[31] V. B.- Sánchez and C. A.- Sahuquillo, "Entrepreneurial Intention Among Engineering Students: The Role of Entrepreneurship Education", European Research on Management and Business Economics, Vol. 24, Issue 1, pp. 53-61, 2018.

[32] C. Botsaris and V. Vamvaka, "Attitude Toward Entrepreneurship: Structure, Prediction from Behavioral Beliefs, and Relation to Entrepreneurial Intention", Journal of the Knowledge Economy volume, Vol. 7, pp. 433460, 2016.

[33] J. Galindo, Handbook of Research on Fuzzy Information Processing in Databases, June 2014. 2008.

[34] A. Baykasołlu and I. Gölcük, "Development of a Novel Multiple-Attribute Decision Making Model Via Fuzzy Cognitive Maps and Hierarchical Fuzzy TOPSIS", Information Sciences, Vol. 301, pp. 75-98, 2015.

[35] S. Müller, "Increasing Entrepreneurial Intention: Effective Entrepreneurship Course Characteristics", International Journal of Entrepreneurship and Small Business, Vol. 13, No. 1, pp. 55-74, 2011.

[36] M. H. I. Witten and E. Frank, Data Mining: Practical Machine Learning Tools and Techniques, 3rd Edition, Morgan Kaufmann, 2011.

[37] P. Tan and M. Steinbach, Introduction to Data Mining: Instructor's Solution Manual", Pearson Addison-Wesley, 2006.

[38] E. Tornikoski and A. Maalaoui, "Critical Reflections - The Theory of Planned Behavior: An Interview with Icek Ajzen with Implications for Entrepreneurship Research", International Small Business Journal: Researching Entrepreneurship, pp. 1-15, 2019.

[39] Ng. Kim-Soon, A. R. Ahmad, and N. N. Ibrahim, "Theory of Planned Behavior: Undergraduates' Entrepreneurial Motivation and Entrepreneurship Career Intention at a Public University", Journal of Entrepreneurship: Research \& Practice, Vol. 2016, pp. 1-14, 2016. 
[40] M. Z. Alam, S. Kousar, and C. A. Rehman, "Role of Entrepreneurial Motivation on Entrepreneurial Intentions and Behavior: Theory of Planned Behavior Extension on Engineering Students in Pakistan", Journal of Global Entrepreneurship Research, Vol. 9, No. 50, pp. 1-20, 2019.

[41] J. N. F. Krueger and A. L. Carsrud, "Entrepreneurial Intentions: Applying The Theory of Planned Behavior", Article in Entrepreneurship, Vol. 5, pp. 315-330, 1993.

[42] S. Sabah, Entrepreneurial Intention: Theory of Planned Behaviour and the Moderation Effect of Start-Up Experience, Entrepreneurship Practice-Oriented Perspectives, 2016.

[43] C. Tsordia and D. Papadimitriou, "The Role of Theory of Planned Behavior on Entrepreneurial Intention of Greek Business Students", International Journal of Synergy and Research, Vol. 4, No. 1, pp. 23-37, 2015. 